\title{
Electrochemical Hybrid Methods and Sensors for Antioxidant/Oxidant Activity Monitoring and Their Use as a Diagnostic Tool of Oxidative Stress: Future Perspectives and Challenges
}

\author{
Khiena Z. Brainina ${ }^{1,2, *(D)}$ and Yan E. Kazakov ${ }^{1}$ (D) \\ 1 Sensors Technology Center, Ural State University of Economics, 62/45, 8 Marta/Narodnoi Voli St., \\ Yekaterinburg 620144, Russia; yankaz@yandex.ru \\ 2 Laboratory of sensor technologies in eco-, bio-, and pharmaceutical monitoring, Ural Federal University, \\ Mira St. 19, 620002 Yekaterinburg, Russia \\ * Correspondence: baz@usue.ru
}

Received: 15 August 2020; Accepted: 25 September 2020; Published: 26 September 2020 updates

\begin{abstract}
The terminology used in electrochemical methods which are used to generate the measured signal in antioxidant/oxidant activity (AOA/OA) sensors is briefly considered. The review presents a hybrid version of electrochemical methods for the determination of AOA/OA. Invasive electrochemical methods/sensors for AOA/OA of blood/serum/plasma, and non-invasive ones for semen, sweat, saliva and skin determination are described. AOA/OA sensors application in health estimation, cosmetology, food and nutrients is presented. Attention is paid to widely described approaches and technologies used in chemical/biochemical sensors. It will be considered as base/prototypes for developing sensors of the kind for AOA/OA determination. Prospects for the development of wearable, written sensors and biosensors are considered. Miniature and wireless sensors will allow for the monitoring of the patient's state, both at the bedside and far beyond the hospital. The development of wearable self-powered written and printed sensors is an important step towards personalized medicine.
\end{abstract}

Keywords: sensors; antioxidant/oxidant activity; oxidative stress; hybrid electrochemical methods; biofluids/tissue

\section{Introduction}

"Chemistry widely spreads its arms in human existence" [1] (p. 362). This idea by M. Lomonosov fully applies to analytical chemistry and all its sections, in particular, clinical, pharmaceutical, food, and cosmetic methods aimed at the development of personalized medicine are of particular importance. Sensors and sensor systems that provide information on site and in situ, in vivo and in vitro play a significant role in this process.

The role of redox reactions in the homeostasis of aerobic organisms is well known [2]. The imbalance between oxidant production in the respiratory chain of mitochondria and the lack of antioxidant defense system activity results in oxidative stress (OS), which plays the central role in the main common pathological processes (cancer, ischemia, inflammation). Because the redox reactions are non-specific, there is a large problem to assess the severity and duration of oxidative stress, its location and activity in different organs and tissues.

The potentiometric method, where a mediator system is used for generating the signal-forming substances, was suggested earlier [3-5], for the estimating of OS considering the integral antioxidant activity (AOA) as its criterion. Later, taking into account that analytical signal generated by two 
different processes occurring simultaneously or successively, authors [6-9] introduced the term "a hybrid variant of potentiometric method" to emphasize the difference from the conventional potentiometric measurements.

It is worth noting two variants of the hybrid potentiometric method (HPM) that are used in the analysis of fluids and the contact hybrid potentiometric method (CHPM) that is designed to be used for the investigation of solids. This term was introduced in $[10,11]$ for the method described earlier $[8,9]$.

The results of AOA/OA of blood serum in healthy volunteers and patients with various diseases (cancer, heart diseases, respiratory diseases) in comparison with normal values in healthy volunteers were presented in our earliest works $[6,8,12]$. The works deal with the problem of AOA correlation with the different laboratory, biochemical and clinical values, such as full blood count test indicators, inflammation markers; laboratory and clinical markers of cardiovascular diseases, cancer and respiratory diseases, and defines the possible place and value of antioxidant activity monitoring in early and differential diagnostics of the abovementioned pathology. Thus, AOA at inflammation can also give predictive important information. Inflammation is a common pathological process, playing an important role in the pathogenesis of infectious and some non-infectious diseases (cardiovascular diseases and some types of cancer). Therefore, the treatment of inflammation can possibly prevent the occurrence of related diseases. An important feature of inflammation is the rise of reactive oxygen species (ROS), which is manifested in a decrease in AOA. Scavenging of ROS by antioxidants can relieve inflammation as well as inhibit the occurrence of related diseases [13]. Thus, monitoring of the AOA of the biological environment is attributed not only to data as they are, but it can also give predictive important information.

The relationship between oxidative stress (OS) and AOA/OA as its integral criterion which characterizes the state of human health has become clearer in recent decades as the result of research in this field carried out in chemical, biological and medical laboratories all over the world. The term "oxidative stress" refers to the imbalance between the production of oxidants (hydrogen peroxide, organic hydro-peroxides, nitric oxide, oxygen and nitrogen reactive species, etc.), which generate oxidation processes, and exhaust activity of the system of antioxidant protection of the living organism. That is why monitoring of AOA/OA as an integral indicator of health status is the important task.

The evolution of vision about oxidative (oxidant) stress and its role in different pathologies led to the development of methods for the monitoring of OS and understanding that the evaluation criterion in this case is the AOA/OA of the environment, and the special analytical methods for its measurement must be developed.

The occurrence and manifestation of OS are determined by the electron-donor-acceptor properties of the investigating biological system. The use of electrochemical methods, as the most appropriate to the nature of the studied phenomenon, to obtain information about them is preferable.

The purpose of the review is: (i) to systematize data on hybrid electrochemical method determination of AOA/OA, paying attention to variants developed for liquids and condensed media analysis; (ii) to consider sensory support for AOA/OA monitoring of: biological fluids (blood plasma, saliva, etc.), skin, food, cosmetics, etc.; (iii) to describe an application of these sensors as the diagnostic tool of OS estimation; and (iv) to try to forethought future perspectives and challenges

The following questions will be considered:

- the current state of sensor development to determine AOA/OA (concentration of determined compounds);

- terminology, importance of AOA/OA units expression standardization;

- hybrid variants of chronopotentiometry and chronoamperometry as a tool for $\mathrm{AOA} / \mathrm{OA}$ determination

- invasive and non-invasive electrochemical methods and sensors for estimation of AOA/OA of biological fluids and tissue (blood/serum (plasma), semen, sweat, saliva and skin.

- application of sensors for testing of the AOA/OA state of healthy volunteers and patients with various diseases in compare with clinical and medical features; 
- AOA of plants, food, nutrients, raw materials, drugs and cosmetics; the future perspectives of AOA/OA electrochemical estimation.

Despite the huge amount of research devoted to the development and use of chemical and biochemical methods [12-14] and sensors $[10,15]$, the terminology in this area is not clear enough. This applies both to the concept of AOA itself [7] and to the composition and design of sensors.

Below, when considering methods and sensors for determining AOA/OA, we use the information provided in [7], and IUPAC recommendations [16] in the field of chemical and biochemical sensor terminology.

A chemical sensor is a device that transforms chemical information that depends on the concentration of a specific sample component into an analytically useful signal. The above-mentioned chemical information can be obtained as a result of the chemical reaction of the analyzed substance or as a result of the changes in physical properties of the investigated system.

Chemical sensors contain two main functional units: the receptor part and the transducer part. Some sensors may include a separator, which is, e.g., a membrane. In the receptor part of the sensor, chemical information is converted into a form of energy, which can be transmitted to the measuring circuit by a transducer. The receptor provides sensory selectivity, the transducer does not show selectivity.

Electrochemical devices convert the effect of the electrochemical interaction between the analyte and the electrode into a useful signal. The following approaches should be noted:

(a) voltammetric and amperometric sensors, in which the current is measured: in these cases, chemically inert or active and modified electrodes are used.

(b) potentiometric sensors in which the potential of the indicator electrode is measured against a reference electrode [16].

Taking into account the above definitions, ox/red electrodes can be classified as sensors, and electrochemical cells containing a platinum electrode and a reference electrode (RE), along with, for example, wearable or contact electrodes in combination with screen-printed silver/chloride electrodes, can be considered as sensor systems.

\section{Methods}

Electrochemical methods are based on electrochemical oxidation-reduction reactions occurring on the interface electrode or in the volume of the solution, the result of which is recorded [14]. Processes involving prior or simultaneous ongoing chemical reactions can be considered as hybrid variants $[6-8,10,11,17]$. Those variants can be considered as preferable for AOA/OA determination.

Two realizations of these variants should be mentioned:

1. The soluble mediator (signal generating) system is introduced into the solution to be analyzed

2. The signal generating system containing sparingly soluble compounds is placed on the surface of the electrode.

In the first approach (the use of soluble mediator system) the following reactions to determine $\mathrm{AOA} / \mathrm{OA}$ serve as a signal, forming in the first case:

$\mathrm{Fe}(\mathrm{III})+\mathrm{AO}=\mathrm{Fe}(\mathrm{II})+\mathrm{AO}_{\mathrm{ox}}$ in antioxidants concentration determination and

$\mathrm{Fe}(\mathrm{II})+\mathrm{Ox}=\mathrm{Fe}(\mathrm{III})+\mathrm{Ox}_{\text {red }}$ in oxidants concentration determination.

The water soluble mediator system is introduced into the analyzed solution.

The sources of information on AOA/OA (analytical signal) are:

1. The electrode potential shift that is observed when the sample is introduced into the mediator system (chronopotentiometric variant) [3,5];

2. The increment of $\mathrm{K}_{4}\left[\mathrm{Fe}(\mathrm{CN})_{6}\right]$ oxidation current, resulting from the interaction of the $A O$, containing in the sample, with the oxidized form of the mediator system $\mathrm{K}_{3}\left[\mathrm{Fe}(\mathrm{CN})_{6}\right]$ previously introduced into the solution (chronoamperometric version) [17]. 
AOA/OA determination using potentiometric method is based on the equilibrium between oxidized and reduced forms of mediator system (Nernst equation):

$$
E=E_{0}+b \cdot \lg \frac{f_{0 x} C_{0 x}}{f_{\text {red }} C_{r e d}}
$$

where $b=2.3 \frac{R T}{n F} ; f$-activity coefficients, in further calculations of $\Delta E f$ disappears; $E$-the potential of the system in the initial state, V. $\mathrm{C}_{\mathrm{Ox}}$ - concentration of the oxidized form of the mediator system, M; and $C_{\text {Red }}$ - concentration of the reduced form of the mediator system, $M$.

The introduction of an antioxidant or oxidant into the solution leads to a shift in the balance between its components and, accordingly, to the potential shift.

Since the above mentioned reactions go almost to the end, we can assume that stoichiometric ratios are observed between the concentration of antioxidant/oxidant and the components of the mediator system. Then, potential shift serves as analytical signal.

After the introduction of the sample containing antioxidants into the solution, the potential of the mediator system is expressed as follows:

$$
E_{1}=E_{0}+b \cdot \lg \frac{f_{0 x}\left(C_{0 x}-X\right)}{f_{r e d}\left(C_{r e d}+X\right)}
$$

where $E_{1}$ - potential of the system measured after the introduction of the analyzed sample, V; $X$-the concentration of antioxidants in the solution after the introduction of the analyzed sample into it, mM-eq.

After the introduction of a sample containing oxidants into the solution, the potential of the mediator system is expressed as follows:

$$
E_{1}=E_{0}+b \cdot \lg \frac{f_{0 x}\left(C_{0 x}+X\right)}{f_{\text {red }}\left(C_{\text {red }}-X\right)}
$$

where $E_{1}$-potential in the system measured after the introduction of the analyzed sample, $X$-the concentration of oxidants in the solution after the introduction of the analyzed sample, $\mathrm{mM}$-eq.

Using the value $\Delta E=E_{1}-E$, it is easy to calculate

$$
\begin{aligned}
& X=A O A=\frac{C_{0 x}-\alpha C_{r e d}}{1+\alpha} \\
& X=O A=\frac{\alpha C_{r e d}-C_{0 x}}{1+\alpha}
\end{aligned}
$$

Or

$$
X= \pm \frac{C_{0 x}-\alpha C_{r e d}}{1+\alpha}
$$

where «+» for $\mathrm{AOA} ;$ «-» for $\mathrm{OA} ; \alpha=\frac{C_{o x}}{C_{r e d}} \cdot 10^{\frac{\left(E_{1}-E\right) n F}{2.3 R T}}$.

In the second case (chronoamperometric method), as a source of information about AOA (the total content of antioxidants in the sample), the current of potassium ferrocyanide $\left(\mathrm{K}_{4}\left[\mathrm{Fe}(\mathrm{CN})_{6}\right]\right)$ oxidation, formed as a result of the reaction of antioxidants with $\mathrm{K}_{3}\left[\mathrm{Fe}(\mathrm{CN})_{6}\right]$, introduced into the solution beforehand is used.

$A O A$ is calculated using the formula:

$$
A O A=C_{a d d} \cdot \frac{\Delta I_{\text {sample }}}{\Delta I_{\text {add }}}
$$

where $A O A$-antioxidant activity (total content of antioxidants in the sample), $\mathrm{mM}-\mathrm{eq}$; $C_{a d d}$-concentration (in the electrochemical cell) of a standard addition of $\mathrm{K}_{4}\left[\mathrm{Fe}(\mathrm{CN})_{6}\right]$, 
$\Delta I_{\text {sample }}$-oxidation current increment of $\mathrm{K}_{4}\left[\mathrm{Fe}(\mathrm{CN})_{6}\right]$, obtained as the result of the interaction of the sample with $\mathrm{K}_{3}\left[\mathrm{Fe}(\mathrm{CN})_{6}\right] ; \Delta I_{\text {add }}$ —oxidation current increment of $\mathrm{K}_{4}\left[\mathrm{Fe}(\mathrm{CN})_{6}\right]$, introduced into the analyzed mixture.

The second approach (the use of the signal generating system, containing sparingly soluble compounds, immobilized on the electrode surface) is demonstrated by results described in the A. Karyakin's group works [18-27] dedicated to the development of a hydrogen peroxide sensor. This type of sensor is used in biosensors based on enzymes oxidases, a component of disinfection means, and as a diagnostic criteria of pathologic conditions. The works mentioned above demonstrate a method of $\mathrm{H}_{2} \mathrm{O}_{2}$ monitoring-amperometric detection of the $\mathrm{H}_{2} \mathrm{O}_{2}$ concentration using as a sensor electrode, modified by Prussian blue (PB). Processes in the system $\mathrm{Fe}^{3+} / \mathrm{Fe}^{2+}$ of $\mathrm{PB}$ serve as the signal generation, which provides information about the concentration of $\mathrm{H}_{2} \mathrm{O}_{2}$ in the sample. The application of this approach for antioxidant determination is presented in the work [28].

Electrode modified by a reversible redox couple and (3,4-ethylenedioxythiophene (PEDOT) immobilized on its surface served as the chronopotentiometric sensor. The chemical reaction occurring between $\mathrm{K}_{3}\left[\mathrm{Fe}(\mathrm{CN})_{6}\right]$ with a dissolved analyte serves as the signal generating process. The above mentioned method and sensor were used for some juices analysis [29].

\subsection{Invasive and Non-Invasive Electrochemical Methods in Estimation of AOA/OA of Bioliquids (Blood/Serum} (Plasma), Semen, Sweat, Saliva) and Tissue (Skin)

Two approaches to electrochemical methods and sensors application for biological systems analysis are described in the scientific literature: invasive, in [4,6,8,11], and non-invasive [30-34] ones.

The first variant requires blood sampling that is introduced into the solution, containing a mediator- $\mathrm{K}_{3}\left[\mathrm{Fe}(\mathrm{CN})_{6}\right] / \mathrm{K}_{4}\left[\mathrm{Fe}(\mathrm{CN})_{6}\right]$. Potential shift that is a consequence of the chemical interaction of antioxidants with potassium hexacyanoferrate (III) serves as the source of information.

Noninvasive variant is based on the interaction of the oxidized component of mediator system introduced into the gel [34] or membrane [35] impregnated with the electrolyte solution, containing a mediator system or $\mathrm{K}_{3}\left[\mathrm{Fe}(\mathrm{CN})_{6}\right]$ with antioxidants, which diffuse out of the skin. Two modes of measurements are used in this case: (i) a potential shift if the matrix contains the mediator system, or (ii) a current if it contains only the oxidized component of the mediator system as a reagent.

\subsection{Sensors}

As a rule, to determine the integral $\mathrm{AOA} /$ concentration of the object under study, the indicator electrodes are manufactured by screen printing using carbon or Pt pastes $[6,34,36-39]$ or new materials, for example, carbon veil [40]. In a number of works, to improve the quality of the electrode, nanomaterials are deposited on its surface [41-50].

Standard silver chloride electrodes are used as the reference electrodes for the analysis of liquids, and single-use standard skin medical electrodes for electrocardiography [34] or (in later studies) silver/chloride electrodes [9] manufactured from conductive silver paste PP-17C from RPE Delta-Pastes Ltd. (Russia), which is placed on a nonconductive substrate using screen printing technology, were used for non-invasive (skin) analysis. The problem of the instability of these electrodes' potential in the presence of mediator system was solved by modifying the surface of such electrodes with a mixed precipitate of chloride and silver ferricyanide [9].

The combination of the indicator electrodes, reference electrodes, gel or membrane described above is the basis of various sensory systems. So, a system consisting of a platinum indicator and standard reference electrode is used in analysis of liquids, and a mediator system is introduced into the analyzed solution [3,4]. The other sensory systems were designed to study condensed systems, in particular, for non-invasive skin AOA/OA evaluation [10]. 


\subsection{Measuring Means}

The potential difference between the electrodes or the current flowing in the system is measured. Instead of the commonly used scheme including an energy source and a three-electrode sensor, the authors of the patent [51] proposed replacing the power supply and three-electrode sensor with an ammeter and two-electrode sensor. Concentration of the analyte (hydrogen peroxide) in the analyzed solution can be found using a preliminary built calibration curve, which limits the application of this method for the analysis of solutions. The original scheme for measurements is shown on Figure 1a. The advantage of this approach is that the measurements are carried out simultaneously in similar conditions and it saves time.

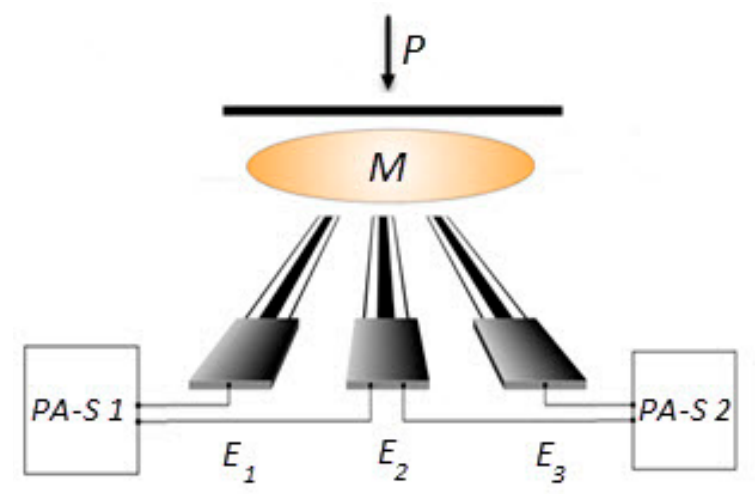

(a)

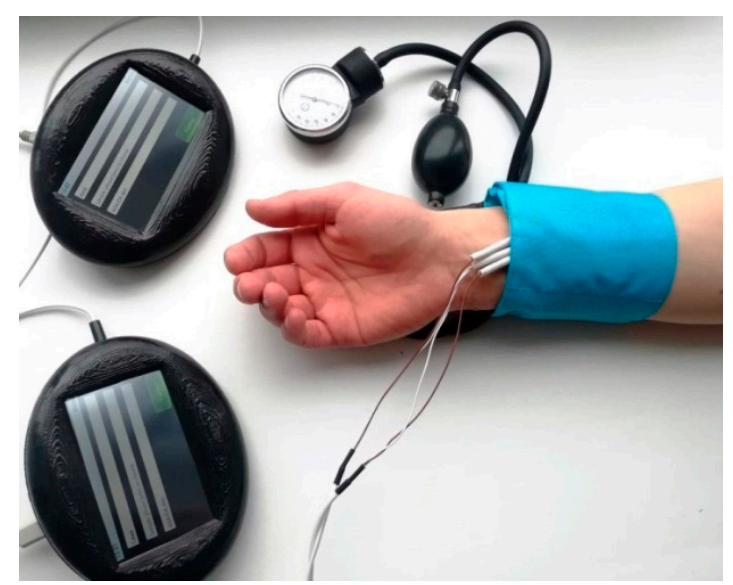

(b)

Figure 1. Measuring scheme (a) and photo (b), illustrating the process of skin research. $E_{1}, E_{2}$, $\mathrm{E}_{3}$-electrodes; M: membrane; PA-S 1 and PA-S 2: potentiometric analyzers. Reprinted from [10].

Sensors of AOA in Medicine

The AOA/OA of blood plasma/serum, sperm, and saliva was studied using the hybrid potentiometric method (HPM) with platinum screen printed sensors $[4,6,8,41]$ used as indicators and a standard reference electrode. The study was conducted in accordance with the Declaration of Helsinki, and the protocol of the study was approved by the Ethics Committee of "Medical Technologies" JSC (Project identification code 16-01-18 MT-AO), in accordance with the rules of Good Clinical Practice. Testing of the AOA/OA state of healthy volunteers and ill patients in comparison with clinical and medical features was done mainly using an invasive variant of HPM and the mentioned sensory system, immersed into phosphate buffer solution (PBS), containing a signal-generating mediator and the analyzed sample. All patients who were involved in the study provided informed consent. The patients were advised to avoid fatty foods and alcohol use the day before, and smoking the morning before the blood uptake. The blood sampling procedure was performed after fasting early in the morning (7.00-8.30). Blood was taken by venipuncture into polyethylene terephthalate vacuum tubes (Chengdu Puth Medical Plastics Packaging Co., Ltd., Chengdu, China) containing a coagulation activator (SiO2), followed by centrifugation at a speed of $3500 \mathrm{rpm}$ for $15 \mathrm{~min}$ using centrifuge SM-6M (SIA ELMI, Latvia). The venipuncture was performed by an experienced member of staff to minimize the possible negative influence of pain and stress, related to an invasive procedure, on the AOA/OA level. The potential influence of smoking and food composition, especially dietary fat, on the OS and AOA is obvious. In our previous work [8], the possible dependence of AOA/OA level on the blood uptake time (starvation period) was discussed (Table 1), but this phenomenon still requires a definitive explanation, although the most appropriate explanation is the development of OS as a non-specific manifestation of the general adaptation syndrome during starvation. 
Table 1. The dependence of AOA of the blood serum of healthy volunteers on the starvation period. Reprinted from [8], with changes.

\begin{tabular}{ccc}
\hline Subgroup & AOA, $\mathbf{m M - e q}$ & $\boldsymbol{t}$-Test \\
\hline Men $(n=42)$ & $1.21 \pm 0.26$ & $\begin{array}{c}\text { non-significantly } \\
\text { difference }\end{array}$ \\
\hline Women $(n=68)$ & $1.22 \pm 0.30$ & - \\
\hline Time of blood sampling: & - & \multirow{2}{*}{ significantly difference } \\
\hline without starvation $(n=36)$ & $1.42 \pm 0.29$ & \\
\hline after starvation period $(n=74)$ & $1.12 \pm 0.23$ & \\
\hline
\end{tabular}

The future revealing of the subtle mechanisms of the starvation influence on the AOA/OA can be useful in dietetics, and in complex approaches to the diagnostics and monitoring of the efficacy and safety of the treatment of obesity, bulimia, and other eating disorders. It is obvious that all the rules of preparation for analysis and all stages of blood collection must be strictly observed in order to avoid accidental preanalytical errors in the assessment of AOA/OA (for example, smoking before blood collection). Examples of the application of noninvasive variants of contact hybrid electrochemical investigation of skin with the use of one of sensory systems described above and special scheme for that were given in [10,34,35]. The measuring scheme used is shown in Figure 1.

Such a circuit allows the correct results to be obtained, due to the fact that measurements are carried out at the same time in similar conditions. Another advantage of the measurement method proposed in this work [10] is the reduction in time, as two results are obtained simultaneously in one measuring period. The reliability of the contact of the electrodes with the membrane and the object under study is ensured by placing a load of $70 \mathrm{~g}$ on the plate placed on the sensory system (when working with model systems) or pressing the sensory system to the skin with the help of a cuff (with the level of pressure equal to $35-40 \mathrm{~mm} \mathrm{Hg}$ ).

The complexity of using the AOA/OA indicator to assess a particular clinical condition or disease consists in the non-specificity of OS and AOA. AOA/OA cannot be a quantitative measure of OS of a specific disease or a diagnostic criterion, since it reflects the level of OS, which is a manifestation of the main typical pathological processes. Preliminary data show the significant difference between AOA/OA level in various diseases, especially promising data concern the proof of dramatic decrease in the AOA/OA level in cancer [8]. Some promising results were obtained during AOA/OA measurement of sperm [12] in different types of infertility and saliva [6]. The potential mechanisms of AOA/OA changes can be divided in two groups: common and specific (unique).

Common: each disease carries in its basic mechanisms the common (typical) pathologic processes, and OS plays one of the key roles in this process developing. The OS activation may differ to a greater or lesser extent in different locations (out of or into the cells and organelles), organs and tissues.

Specific (more or less): according to the unique mechanisms for each nosology (disease), this deals with the specific cells and specific organs tissues. Therefore, the disease may have a unique chemical signature that changes in epigenome, metabolome, etc. and OS activity. The correlation rules of such relationships are sophisticated but can be the specific for each group of diseases, and such an idea should be studied, but the difficulty of such a view is evident. Therefore, from this perspective it seems to measure OS and make its estimation together with specific markers which can influence the $\mathrm{AOA} / \mathrm{OA}$ and can be accepted as "the signature" of concrete disease, for example, the group of markers - AOA + cholesterol + glucose in cardiovascular diseases. The specific algorithms of mathematical analysis can be possibly useful and necessary (for example, in prospective neural networks).

The current method of application of the electrochemical hybrid methods of AOA/OA measurement in medical practice seems to be to develop it as a cheap and reliable tool for the integral health status assessment, and use the patient's low AOA/OA level as a "red flag" for the physician to make subsequent, more specific steps for the deep and precise diagnostics and/or treatment of the patient. The advantages of sensors and sensor-based devices are obvious-safety (especially for noninvasive 
AOA/OA measurement), low cost, simplicity and the ability to screen a large number of patients, and the first task is to standardize the parameters of AOA/OA and the criteria of its normal and abnormal ranges, and their accordance with the pathologic situations of different causes and severities. This prospective method of OS study comprises the development of tools and methods for measuring oxidants in blood. The difficulty of oxidants measurement can be explained by the very short lifetime of ROS, because they are scavenged by antioxidants. Special high-quality and well-designed studies are needed in this field.

\subsection{Sensors Application in Determination of Antioxidant Activity of Plants, Nutrients, Food, Drugs and Cosmetics}

An approach analogous to that described above as a tool for biologic liquids analysis was mainly used for determination of the AOA of plants, nutrients, food, drugs and cosmetics [3,52]. Problems arising in the analysis of solids are solved by preliminarily dissolving or dispersing the sample to the state of microemulsions or microsuspensions [53]. For example, in [36], cosmetic cream mixed with water was emulsified in an ultrasonic field. In this work, the possibility to determine oxidants $\left(\mathrm{H}_{2} \mathrm{O}_{2}\right)$ as well as antioxidants, using one and the same approach, was shown.

The measuring electrode $(\mathrm{Pt})$ and reference (ECG-type) electrode in the presence of the mediator system $\mathrm{K}_{3}\left[\mathrm{Fe}(\mathrm{CN})_{6}\right]+\mathrm{K}_{4}\left[\mathrm{Fe}(\mathrm{CN})_{6}\right]$ introduced into the gel were used to study the impact of cosmetic creams on skin AOA [36].

Optimized conditions (scheme and sensory system proposed later [10,35]) were used in non-invasive skin antioxidant activity evaluation (Figure 2).

(a)
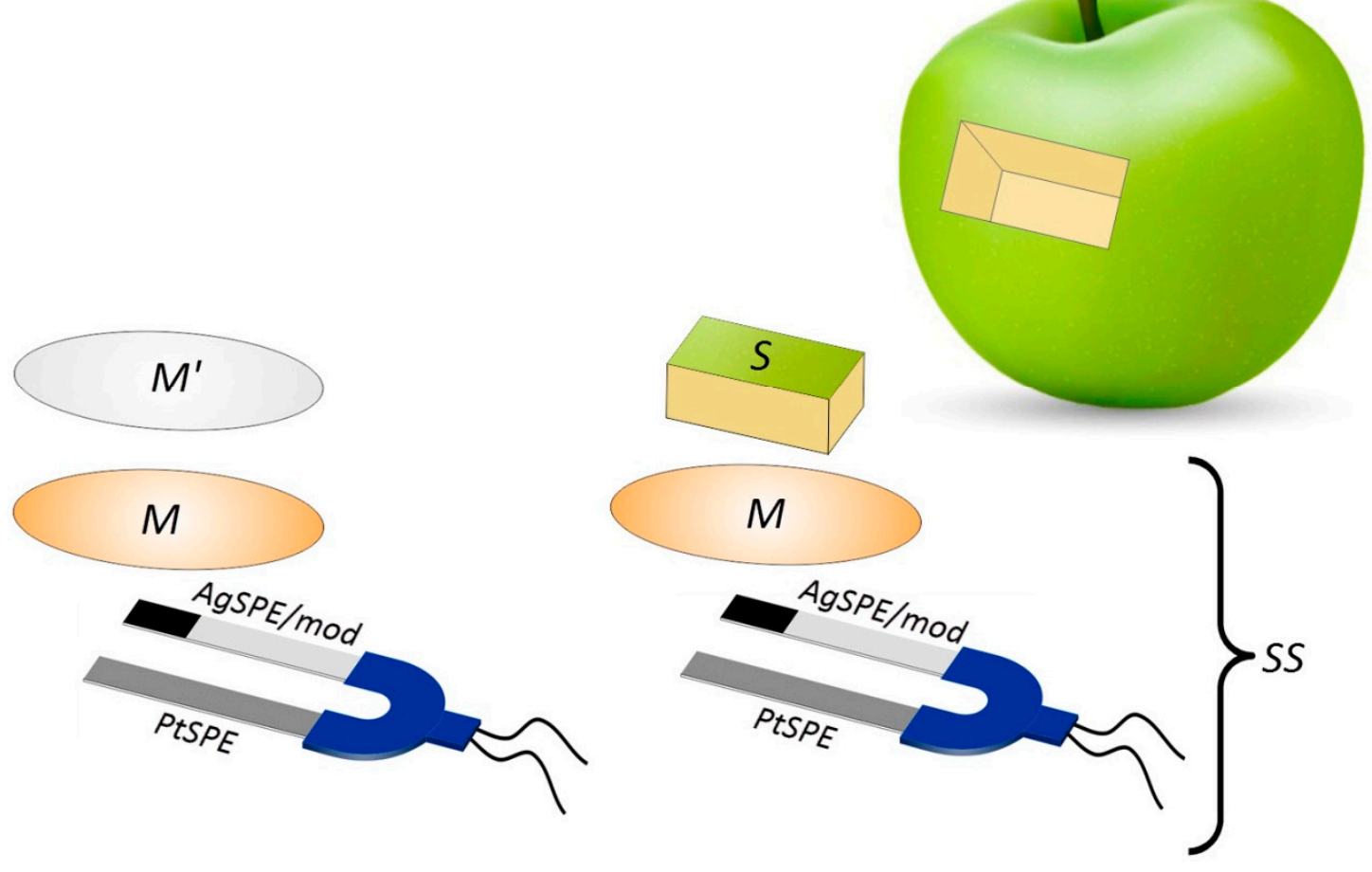

(b)

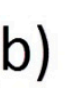

Figure 2. Schemes: (a) sensory system for model antioxidant determination; (b) sensory system in assessing of sample AOA/OA. $\mathrm{M}$ is the membrane impregnated with a solution of the mediator $\left[\mathrm{Fe}(\mathrm{CN})_{6}\right]^{3-/ 4-} ; \mathrm{M}^{\prime}$ : membrane impregnated with a model antioxidant solution; $\mathrm{S}$ : slice of the test sample; PtSPE-: platinum screen-printed electrode; AgSPE/mod: modified silver screen-printed electrode; SS: sensory system. Reprinted from [11], with the permission of Elsevier. 
A sensory system, which included screen-printed platinum and silver/silver chloride, modified by a mixed precipitate of silver chloride and silver ferricyanide electrodes, and a membrane, impregnated with mediator, serving for signal generation in contact hybrid potentiometric measurements, was used for the determination of the AOA/OA of fruits and vegetables. Obtained data [11] are presented in Table 2.

Table 2. The AOA of fruits and vegetables, obtained by CHPM. Sensory system, including platinum, silver/silver chloride screen-printed electrodes and a membrane, was used. Reprinted from [11] with the permission of Elsevier.

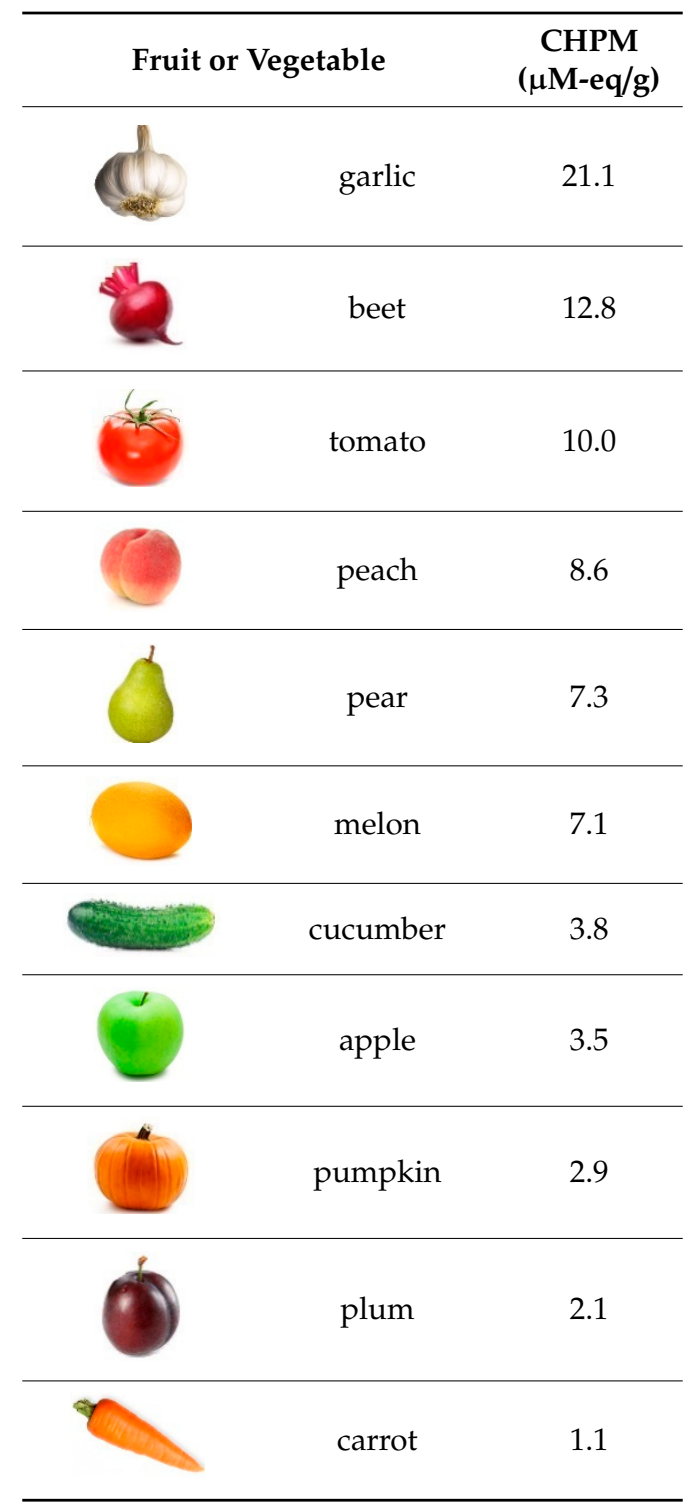

\subsection{Future Perspectives and Challenges}

The 21st century is the time for communications, in particular personal communications; this makes it possible to develop a new level of medicine-personalized medicine and telemedicine [54]. An example of this new concept of personalized medicine is the Wireless Body Area Network (WBAN) [55]. A WBAN comprises a number of health sensors that collect the information of vital parameters of a human body. The development of sensory technologies is a prerequisite for the creation or extension of methods to be used in telemedicine, sports medicine, the quality control of drugs, products, and cosmetics-all that determines human health. Information about individual 
different laboratory biochemical and clinical indicators such as glucose, cholesterol, etc. is important for routine clinical practice and decision making in medicine. On the other hand, the criteria for health status in general is of great importance. There are a few important goals to be achieved in the near future: to increase the number of defined markers and to develop sensors (methods and design) for determining parameters that give general information about the state of health, to create multisensors or chips for obtaining information about a number of parameters, to use artificial intelligence for processing information and obtaining conclusions about the state of human health, to carry out private and general diagnostics, and to develop new sensors or their new variants for invasive and non-invasive diagnostics, and sensors for use in vivo.

Two tasks should be solved: (i) developing the convenient design of these sensors and (ii) finding and investigating the specific approaches for analytical signal generation. Different devices can be manufactured in one and the same design. The sensor selectivity is determined by receptor selection and mode of measurement. Examples are described in the reviews and references in it $[56,57]$. Chemical (biochemical) sensors for skin are developed to be used as a detector of different biological markers. Unfortunately, antioxidants are not included in their number. Nevertheless, electrochemical methods and sensors of AOA/OA, as it was shown above, give useful data for health and pathology evaluation. The study of AOA/OA of skin demonstrated that noninvasive methods of OS monitoring are of interest in such fields as health screening, disaster medicine, sports medicine, cosmetology and nutrition, as they enable one to use AOA/OA as a prediagnostic (screening) criterion for examining large groups of the population, while eliminating the need for invasive procedures.

Prospects for the use of the AOA/OA indicator to assess the degree of adaptation/disadaptation of the body to chronic psychogenic stress, adverse climatic (regions with a cold climate, with an intensive solar radiation, etc.) conditions, adverse and severe working conditions, and excessive load in professional sport, will open up new possibilities in medicine. Often, these conditions are combined with low availability of qualified medical care, and/or with very high costs of medical care-for example, in remote and inaccessible regions and settlements, regions and countries with poverty and poor food supply, and it requires the development of new sensor designs. In this regard, we describe the application of electrochemical methods for the creation of sensor technologies for the rapid assessment of antioxidant activity, with the possibility of a joint application with an assessment of other key biochemical parameters (glucose, cholesterol, creatinine, etc.). The advantages and features of a non-invasive method for determining AOA/OA (skin), the possibility of using the method for mass medical screening, for use in fitness and sports medicine, in remote and inaccessible settlements, including using telemedicine, are the trends of the area.

We consider the data presented in reviews [56-63], devoted to different portable and wearable sensors, can serve as a basis for the development of portable and wearable sensors for oxidative stress monitoring and AOA/OA determination. Wearable sensors are soft, flexible and stretchable devices designed to monitor clinically important human health indicators, and they are usually electrochemical [64-69]. Miniature and wireless sensors will allow for the constant monitoring of the patient's health, both at the bedside and far beyond the hospital. At the same time, due to the modern built-in data exchange systems, doctor's recommendations can be received at a distance. Thus, the development of wearable self-powered and written sensors is an important step towards personalized medicine.

Serious problems should be solved before the sensors of this kind will find application in practice: data acquisition, transfer and their interpretation. It is also necessary to establish whether correlations exist between measuring parameters that are characteristic for the skin and blood. The application of WBAN technologies, inclusion of new sensors into the system and using smartphones opens up a revolutionary era in the development of on-site monitoring methods, creates new telemedicine capabilities and paves the way from "test tubes to smartphones".

Funding: This research received no external funding. 
Conflicts of Interest: The authors declare no conflict of interests. The sponsors had no role in the design, execution, interpretation, or writing of the study.

\section{References}

1. Lomonosov, M.V. A word about the benefits of chemistry, in the public meeting of the imperial academy of sciences in 6 September 1751, spoken by Mikhail Lomonosov. In Complete Works. Works on Physics and Chemistry. 1747-1752 (in Russian); Publishing House of the Academy of Sciences of the USSR: Moscow, Leningrad, 1951; Volume 2, p. 362.

2. Neha, K.; Haider, M.R.; Pathak, A.; Yar, M.S. Medicinal prospects of antioxidants: A review. Eur. J. Med. Chem. 2019, 178, 687-704. [CrossRef]

3. Brainina, K.Z.; Ivanova, A.V.; Sharafutdinova, E.N.; Lozovskaya, E.L.; Shkarina, E.I. Potentiometry as a method of antioxidant activity investigation. Talanta 2007, 71, 13-84. [CrossRef]

4. Brainina, K.Z.; Alyoshina, L.V.; Gerasimova, E.L.; Kazakov, Y.E.; Ivanova, A.V.; Beykin, Y.B.; Belyaeva, S.V.; Usatova, T.I.; Khodos, M.Y. New electrochemical method of determining blood and blood fractions antioxidant activity. Electroanalysis 2009, 21, 618-624. [CrossRef]

5. Ivanova, A.V.; Gerasimova, E.L.; Brainina, K.Z. Potentiometric study of antioxidant activity: Development and prospects. Crit. Rev. Anal. Chem. 2015, 45, 311-322. [CrossRef]

6. Brainina, K.Z.; Varzakova, D.P.; Kazakov, Y.E.; Vidrevich, M.B. Noninvasive electrochemical antioxidant activity estimation: Saliva analysis. Biointerface Res. Appl. Chem. 2018, 8, 3381-3387.

7. Brainina, K.; Stozhko, N.; Vidrevich, M. Antioxidants: Terminology, Methods, and Future Considerations. Antioxidants 2019, 8, 297. [CrossRef] [PubMed]

8. Kazakov, Y.; Tarasov, A.; Alyoshina, L.; Brainina, K. Interplay between antioxidant activity, health and disease. Biointerface Res. Appl. Chem. 2020, 10, 4893-4901.

9. Brainina, K.Z.; Tarasov, A.V.; Vidrevich, M.B. Silver Chloride/Ferricyanide-Based Quasi-Reference Electrode for Potentiometric Sensing Applications. Chemosensors 2020, 8, 15. [CrossRef]

10. Brainina, K.; Tarasov, A.; Khamzina, E.; Kazakov, Y.; Stozhko, N. Disposable potentiometric sensory system for skin antioxidant activity evaluation. Sensors 2019, 19, 2586. [CrossRef]

11. Brainina, K.; Tarasov, A.; Khamzina, E.; Stozhko, N.; Vidrevich, M. Contact hybrid potentiometric method for on-site and in situ estimation of the antioxidant activity of fruits and vegetables. Food Chem. 2020, 309, 125703. [CrossRef]

12. Kazakov, Y.; Khodos, M.; Vidrevich, M.; Brainina, K. Potentiometry as a tool for monitoring of antioxidant activity and oxidative stress estimation in medicine. Crit. Rev. Anal. Chem. 2019, 49, 150-159. [CrossRef] [PubMed]

13. Sochor, J.; Dobes, J.; Krystofova, O.; Ruttkay-Nedecky, B.; Babula, P.; Pohanka, M.; Jurikova, T.; Zitka, O.; Adam, V.; Klejdus, B.; et al. Electrochemistry as a Tool for Studying Antioxidant Properties. Int. J. Electrochem. Sci. 2013, 8, 8464-8489.

14. Pisoschi, A.M.; Cimpeanu, C.; Predoi, G. Electrochemical Methods for Total Antioxidant Capacity and its Main Contributors Determination: A review. Open Chem. 2015, 13, 824-856. [CrossRef]

15. Kozitsina, A.N.; Svalova, T.S.; Malysheva, N.N.; Okhokhonin, A.V.; Vidrevich, M.B.; Brainina, K.Z. Sensors Based on Bio and Biomimetic Receptors in Medical Diagnostic, Environment, and Food Analysis. Biosensors 2018, 8, 35. [CrossRef]

16. Hulanicki, A.; Glab, S.; Ingman, F. Chemical sensors: Definitions and classification. Pure Appl. Chem. 1991, 63, 1247-1250. [CrossRef]

17. Brainina, K.Z.; Varzakova, D.P.; Gerasimova, E.L. A chronoamperometric method for determining total antioxidant activity. J. Anal. Chem. 2012, 67, 364-369. [CrossRef]

18. Karyakin, A.A.; Karyakina, E.E.; Gorton, L. On the mechanism of $\mathrm{H}_{2} \mathrm{O}_{2}$ reduction at Prussian Blue modified electrodes. Electrochem. Commun. 1999, 1, 78-82. [CrossRef]

19. Komkova, M.; Zarochintsev, A.; Karyakina, E.; Karyakin, A. Electrochemical and sensing properties of Prussian Blue based nanozymes "artificial peroxidase". J. Electroanal. Chem. 2020, 114048. [CrossRef]

20. Komkova, M.A.; Karyakina, E.E.; Marken, F.; Karyakin, A.A. Hydrogen Peroxide Detection in Wet Air with a Prussian Blue Based Solid Salt Bridged Three Electrode System. Anal. Chem. 2013, 85, 2574-2577. [CrossRef] 
21. Mokrushina, A.V.; Heim, M.; Karyakina, E.E.; Kuhn, A.; Karyakin, A.A. Enhanced hydrogen peroxide sensing based on Prussian Blue modified macroporous microelectrodes. Electrochem. Commun. 2013, 29, 78-80. [CrossRef]

22. Sitnikova, N.A.; Mokrushina, A.V.; Karyakin, A.A. Iron triad-mate hexacyanoferrates as Prussian Blue stabilizers: Toward the advanced hydrogen peroxide transducer. Electrochim. Acta 2014, 122, 173-179. [CrossRef]

23. Karpova, E.V.; Karyakina, E.E.; Karyakin, A.A. Iron-nickel hexacyanoferrate bilayer as an advanced electrocatalyst for $\mathrm{H}_{2} \mathrm{O}_{2}$ reduction. RSC Adv. 2016, 6, 103328-103331. [CrossRef]

24. Karpova, E.V.; Shcherbacheva, E.V.; Galushin, A.A.; Vokhmyanina, D.V.; Karyakina, E.E.; Karyakin, A.A. Noninvasive Diabetes Monitoring through Continuous Analysis of Sweat Using Flow-Through Glucose Biosensor. Anal. Chem. 2019, 91, 3778-3783. [CrossRef] [PubMed]

25. Komkova, M.A.; Pasquarelli, A.; Andreev, E.A.; Galushin, A.A.; Karyakin, A.A. Prussian Blue modified boron-doped diamond interfaces for advanced $\mathrm{H}_{2} \mathrm{O}_{2}$ electrochemical sensors. Electrochim. Acta 2020, 339, 135924. [CrossRef]

26. Puganova, E.A.; Karyakin, A.A. New materials based on nanostructured Prussian blue for development of hydrogen peroxide sensors. Sens. Actuators B Chem. 2005, 109, 167-170. [CrossRef]

27. Suprun, E.V.; Karpova, E.V.; Radko, S.P.; Karyakin, A.A. Advanced electrochemical detection of amino acids and proteins through flow injection analysis and catalytic oxidation on Prussian Blue. Electrochim. Acta 2020, 331, 135289. [CrossRef]

28. Karyakina, E.E.; Vokhmyanina, D.V.; Sizova, N.V.; Sabitov, A.N.; Borisova, A.V.; Sazontova, T.G.; Arkhipenko, Y.V.; Tkachuk, V.A.; Zolotov, Y.A.; Karyakin, A.A. Kinetic approach for evaluation of total antioxidant activity. Talanta 2009, 80, 749-753. [CrossRef]

29. Nasri, Z.; Kahlert, H.; Scholz, F. A chronopotentiometric sensor for assays of redox-active compounds. Electrochem. Commun. 2014, 49, 18-20. [CrossRef]

30. Kohen, R.; Fanberstein, D.; Tirosh, O. Non-Invasive Device and Method for Quantitative Determination of Oxidants and/or Antioxidants in the Skin. U.S. Patent No. 6,108,570, 10 October 1995.

31. Kh, Z.; Brainina, E.L.; Gerasimova, M.Y. Khodos, Method of Noninvasive Potentiometric Determination of Oxidant/Antioxidant Activity of Biological Tissues and Device for Its Realization. RF Patent RU 2433405 C1, 23 June 2010.

32. Brainina, K.Z.; Khodos, M.Y.; Sudakova, L.A.; Chernov, V.I. Device for Non-invasive Potentiometric Determination of Oxidant/Antioxidant Activity of Biological Tissues. RF Patent RU 2552942C2, 28 October 2013.

33. Brajnina, K.Z.; Khodos, M.Y.; Zakharov, A.S. Method of Determining Integral Antioxidant/Oxidant Activity of Organic Condensed Media. RF Patent RU 2595814C1, 17 June 2015.

34. Brainina, K.Z.; Galperin, L.G.; Gerasimova, E.L.; Khodos, M.Y. Noninvasive potentiometric method of determination of skin oxidant/antioxidant activity. IEEE Sens. J. 2012, 12, 527-532. [CrossRef]

35. Brainina, K.Z.; Markina, M.G.; Stozhko, N.Y. Optimized potentiometric assay for non-invasive investigation of skin antioxidant activity. Electroanalysis 2018, 30, 2405-2412. [CrossRef]

36. Brainina, K.Z.; Gerasimova, E.L.; Varzakova, D.P.; Kazakov, Y.E.; Galperin, L.G. Noninvasive method of determining skin antioxidant/oxidant activity: Clinical and cosmetics applications. Anal. Bioanal. Electrochem. 2013, 5, 528-542.

37. Markina, M.; Lebedeva, E.; Neudachina, L.; Stozhko, N.; Brainina, K. Determination of antioxidants in human skin by capillary zone electrophoresis and potentiometry. Anal. Lett. 2016, 49, 1804-1815. [CrossRef]

38. Brainina, K.Z.; Tarasov, A.V.; Kazakov, Y.E.; Vidrevich, M.B. Platinum electrode regeneration and quality control method for chronopotentiometric and chronoamperometric determination of antioxidant activity of biological fluids. J. Electroanal. Chem. 2018, 808, 14-20. [CrossRef]

39. Lee, G.-J.; Lee, S.-K.; Kim, J.-M.; Rhee, C.K.; Lee, Y.-K.; Brainina, K.Z.; Kazakov, Y.E. Application Feasibility of Antioxidant Activity Evaluation using Potentiometry in Major Depressive Disorder. Electrochemistry 2014, 82, 264-266. [CrossRef]

40. Brainina, K.Z.; Bukharinova, M.A.; Stozhko, N.Y.; Sokolkov, S.V.; Tarasov, A.V.; Vidrevich, M.B. Electrochemical Sensor Based on a Carbon Veil Modified by Phytosynthesized Gold Nanoparticles for Determination of Ascorbic Acid. Sensors 2020, 20, 1800. [CrossRef] [PubMed]

41. Stozhko, N.; Bukharinova, M.; Galperin, L.; Brainina, K. A nanostructured sensor based on gold nanoparticles and nafion for determination of uric acid. Biosensors 2018, 8, 21. [CrossRef] 
42. Brainina, K.; Stozhko, N.; Bukharinova, M.; Vikulova, E. Nanomaterials: Electrochemical Properties and Application in Sensors. In Nanoanalytics. Nanoobjects and Nanotechnologies in Analytical Chemistry; Chapter 6; Shtykov, S., Ed.; De Gruyter: Berlin, Germany, 2018; pp. 165-222. [CrossRef]

43. Botelho, C.; Pereira, N.; Silva, G.; Menezes, A.; Bezerra, C.; Damos, F.; Luz, R. Photoelectrochemical-assisted determination of caffeic acid exploiting a composite based carbon nanotubes, cadmium telluride quantum dots, and titanium dioxide. Anal. Methods 2019, 11, 4775-4784. [CrossRef]

44. David, M.; Serban, A.; Radulescu, C.; Danet, A.F.; Florescu, M. Bioelectrochemical evaluation of plant extracts and gold nanozyme-based sensors for total antioxidant capacity determination. Bioelectrochemistry 2019, 129, 124-134. [CrossRef]

45. Arman, A.; Üzer, A.; Sağlam, Ş.; Erçă̆, E.; Apak, R. Indirect electrochemical determination of antioxidant capacity with hexacyanoferrate(III) reduction using a gold nanoparticle-coated o-phenylenediamine-aniline copolymer electrode. Anal. Lett. 2019, 52, 1282-1297. [CrossRef]

46. Markina, M.; Stozhko, N.; Krylov, V.; Vidrevich, M.; Brainina, K. Nanoparticle-based paper sensor for thiols evaluation in human skin. Talanta 2017, 165, 563-569. [CrossRef]

47. Apak, R.; Çekiç, S.D.; Üzer, A.; Çelik, S.E.; Bener, M.; Bekdeşer, B.; Can, Z.; Saglam, Ş.; Önem, A.N.; Erçag, E. Novel spectroscopic and electrochemical sensors and nanoprobes for the characterization of food and biological antioxidants. Sensors 2018, 18, 186. [CrossRef] [PubMed]

48. Choleva, T.G.; Kappi, F.A.; Giokas, D.L.; Vlessidis, A.G. Paper-based assay of antioxidant activity using analyte-mediated on-paper nucleation of gold nanoparticles as colorimetric probes. Anal. Chim. Acta 2015, 860, 61-69. [CrossRef] [PubMed]

49. Chou, J.E.; Li, X.; Yin, Y.; Indrisek, N. Determination of antioxidant activities in fruit juices based on rapid colorimetric measurement and characterization of gold nanoparticles. Int. J. Environ. Anal. Chem. 2015, 95, 531-541. [CrossRef]

50. Antuña-Jiménez, D.; González-García, M.B.; Hernández-Santos, D.; Fanjul-Bolado, P. Screen-Printed Electrodes Modified with Metal Nanoparticles for Small Molecule Sensing. Biosensors 2020, 10, 9. [CrossRef] [PubMed]

51. Komkova, M.A.; Karyakina, E.E.; Karyakin, A.A. Method for Determining Concentration of Hydrogen Peroxide in Solution. RF Patent RU 2682568 C1, 3 November 2017.

52. Sharafutdinova, E.N.; Ivanova, A.V.; Matern, A.I.; Brainina, H.Z. Food quality and antioxidant activity. Anal. Control. 2011, 15, 281-286. (In Russian)

53. Brainina, K.; Stozhko, N.; Bukharinova, M.; Khamzina, E.; Vidrevich, M. Potentiometric method of plant microsuspensions antioxidant activity determination. Food. Chem. 2019, 278, 653-658. [CrossRef]

54. Pramanik, P.K.D.; Nayyar, A.; Pareek, G. WBAN: Driving e-healthcare Beyond Telemedicine to Remote Health Monitoring: Architecture and Protocols. In Telemedicine Technologies. Big Data, Deep Learning, Robotics, Mobile and Remote Applications for Global Healthcare; Jude, H.D., Balas, V.E., Eds.; Academic Press: Cambridge, MA, USA, 2019; pp. 89-119. ISBN 9780128169483. [CrossRef]

55. Lont, M.; Milosevic, D.; van Roermund, A.H.M. Wake-up Receiver Based Ultra-Low-Power WBAN; Springer: Berlin, Germany, 2014; pp. 7-28. [CrossRef]

56. Zhao, J.; Guo, H.; Li, J.; Bandodkar, A.J.; John, A. Body-Interfaced Chemical Sensors for Noninvasive Monitoring and Analysis of Biofluids. Trends Chem. 2019, 1, 559-571. [CrossRef]

57. Fan, R.; Andrew, T.L. Perspective-Challenges in Developing Wearable Electrochemical Sensors for Longitudinal Health Monitoring. J. Electrochem. Soc. 2020, 167, 037542. [CrossRef]

58. Seshadri, D.R.; Li, R.T.; Voos, J.E.; Rowbottom, J.R.; Alfes, C.M.; Zorman, C.A.; Drummond, C.K. Wearable sensors for monitoring the physiological and biochemical profile of the athlete. NPJ Digit. Med. 2019, 2, 72. [CrossRef]

59. Yang, Y.; Song, Y.; Bo, X.; Min, J.; Pak, O.S.; Zhu, L.; Wang, M.; Tu, J.; Kogan, A.; Zhang, H.; et al. A laser-engraved wearable sensor for sensitive detection of uric acid and tyrosine in sweat. Nat. Biotechnol. 2020, 38, 217-224. [CrossRef]

60. Bandodkar, A.J.; Jia, W.; Wang, J. Tattoo-based wearable electrochemical devices: A Review. Electroanalysis 2015, 27, 562-572. [CrossRef]

61. Alizadeh, A.; Burns, A.; Lenigk, R.; Gettings, R.; Ashe, J.; Porter, A.; McCaul, M.; Barrett, R.; Diamond, D.; White, P.; et al. A wearable patch for continuous monitoring of sweat electrolytes during exertion. Lab. Chip 2018, 18, 2632-2641. [CrossRef] [PubMed] 
62. Sempionatto, J.R.; Jeerapan, I.; Krishnan, S.; Wang, J. Wearable Chemical Sensors: Emerging Systems for On-body Analytical Chemistry. Anal. Chem. 2020, 92, 378-396. [CrossRef] [PubMed]

63. Goud, K.Y.; Moonla, C.; Mishra, R.K.; Yu, C.; NarayanIrene, R.; Litvan, I.; Wang, J. Wearable Electrochemical Microneedle Sensor for Continuous Monitoring of Levodopa: Toward Parkinson Management. ACS Sens. 2019, 4, 2196-2204. [CrossRef]

64. Montiel, V.R.V.; Sempionatto, J.R.; Campuzano, S.; Pingarrón, J.M.; de Ávila, B.E.F.; Wang, J. Direct electrochemical biosensing in gastrointestinal fluids. Anal. Bioanal. Chem. 2019, 411, 4597-4604. [CrossRef] [PubMed]

65. Barfidokht, A.; Mishra, R.K.; Seenivasan, R.; Liu, S.; Hubble, L.J.; Wang, J.; Hall, D.A. Wearable electrochemical glove-based sensor for rapid and on-site detection of fentanyl. Sens. Actuators B Chem. 2019, 296, 126422. [CrossRef]

66. Hubble, L.J.; Wang, J. Sensing at Your Fingertips: Glove-based Wearable Chemical Sensors. Electroanalysis 2019, 31, 428. [CrossRef]

67. Kim, J.; Campbell, A.S.; de Ávila, B.E.-F.; Wang, J. Wearable Biosensors for Healthcare Monitoring. Nat. Biotechnol. 2019, 37, 389. [CrossRef]

68. Sempionatto, J.R.; Martin, A.; García-Carmona, L.; Barfidokht, A.; Kurniawan, J.F.; Moreto, J.R.; Tang, G.; Shin, A.; Liu, X.; Escarpa, A.; et al. Skin-worn soft microfluidic potentiometric detection system. Electroanalysis 2019, 31, 239-245. [CrossRef]

69. Zhai, Q.; Wang, Y.; Gong, S.; Ling, Y.; Yap, L.W.; Liu, Y.; Wang, J.; Simon, G.P.; Cheng, W. Vertical Gold Nanowires Stretchable Electrochemical Electrodes. Anal. Chem. 2018, 90, 13498-13505. [CrossRef]

(C) 2020 by the authors. Licensee MDPI, Basel, Switzerland. This article is an open access article distributed under the terms and conditions of the Creative Commons Attribution (CC BY) license (http://creativecommons.org/licenses/by/4.0/). 